\title{
First acute psychotic episode: characterization of patients who developed to schizophrenia
}

\author{
Carla Alves Pereira ${ }^{1}$, Bruna Melo ${ }^{1}$, Elsa Monteiro ${ }^{1}$, Alzira Albuquerque ${ }^{1}$, Sofia Ribeiro Pereira ${ }^{1}$,

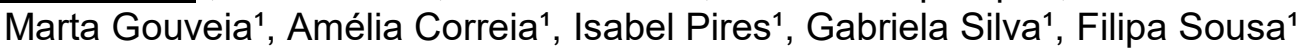 \\ ${ }^{1}$ Department of Psychiatry and Mental Health, Centro Hospitalar Tondela-Viseu, EPE., Viseu, Portugal
}

\section{OBJECTIVES}

To describe the profile of a population of patients with a first psychotic episode who developed to schizophrenia. We intend to highlight the differences in the initial presentation ("first-episode psychosis") between patients who developed to schizophrenia and patients diagnosed with other psychotic disorder.

\section{BACKGROUND AND AIMS}

The term "first-episode psychosis" is sometimes used to identify a person recently identified as acutely psychotic but for whom a formal diagnosis has not yet been established. At present, in the absence of reliable clinical and evolutionary data, it is difficult to determine the consequences of an acute psychotic disorder. Given that the clinical presentation of a first episode of acute psychosis eventually may include various diagnosis, it would be important to identify some differences that could help us clarify the diagnosis as soon as possible.

\section{MATERIAL AND METHODS}

This is a retrospective descriptive study, which involved patients admitted between January 2013 and July 2018, on the First-Episode Psychosis Intervention Team of Tondela-Viseu Hospital, Portugal, with a registered symptom evolution inferior to 6 months.

\section{RESULTS}

Forty six patients were collected. Among those patients with a first acute psychotic episode, 21 patients (45,7\%) progressed to schizophrenia, 19 patients $(41,3 \%)$ to other psychotic disorders while $13 \%$ were lost view (Fig.1).

Among the 21 patients who developed to schizophrenia, the average age of patients was 24.8 years. The majority was single (85,7\%) male $(66,7 \%)$ and $42,8 \%$ had a history of cannabinoid use. Among the 19 patients who developed to other psychotic disorders, the average age of patients was 23.7 years. The majority was single $(84,2 \%)$ male $(63,1 \%)$ and $31,5 \%$ had a history of cannabinoid use (Fig.2).

\section{DIAGNOSTIC EVOLUTION}

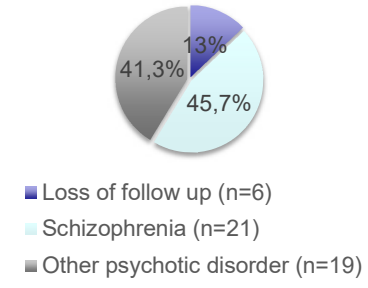

Fig.1 Diagnostic evolution of the patients with a first acute psychotic episode

\begin{tabular}{|c|c|c|}
\hline & $\begin{array}{c}\text { Patients who developed } \\
\text { to schizophrenia }\end{array}$ & $\begin{array}{c}\text { Patients who } \\
\text { developed to other } \\
\text { psychotic disorders }\end{array}$ \\
\hline Average age & 24,8 & 23,7 \\
\hline Marital status & Single $(85,7 \%)$ & Single $(84,2 \%)$ \\
\hline Gender & Male $(66,7 \%)$ & Male $(63,1 \%)$ \\
\hline $\begin{array}{c}\text { History of } \\
\text { cannabinoide use }\end{array}$ & $42,8 \%$ & $31,5 \%$ \\
\hline
\end{tabular}

Fig.2 Characteristics to the initial presentation in a first-episode psychosis

\section{CONCLUSIONS}

In the collected data, there were no significant differences to the initial presentation in a first-episode psychosis which allow us to infer about the diagnostic evolution of patients. So, the long-term evolution of an acute psychotic disorder remains unpredictable. In fact, the severity is related primarily to the risk of developing a schizophrenic disorder. We need more studies in which attention is paid in recent years to recognize and seek the earliest possible factors associated with this development.

\section{REFERENCES:}

Di Forti M, Lappin JM, Murray RM. Risk factors for schizophrenia - all roads lead to dopamine. European Neuropsychopharmacology. 2007;17:101-107.

2. Beck K, Andreou C, Studerus $\mathrm{E}$, Egloff $\mathrm{L}$, heitz $\mathrm{U}$, Ittig $\mathrm{S}$, et al. Long-term rates of remission and late psychotic transition of individuals at risk 